\title{
EFFECT OF JAVANESE TURMERIC ETHANOL EXTRACT ON THE ERADICATION OF CANDIDA ALBICANS BIOFILMS IN EARLY, INTERMEDIATE, AND MATURATION PHASES
}

\author{
BETA BELATRIX, RIA PUSPITAWATI*, ARIADNA ADISATTYA DJAIS \\ Department of Oral Biology, Faculty of Dentistry, Universitas Indonesia, Jalan Salemba Raya No. 4, Jakarta Pusat 10430, Indonesia. \\ E-mail: rpuspitawati2013@gmail.com
}

Received: 20 September 2018, Revised and Accepted: 22 December 2018 and 04 January 2019

\section{ABSTRACT}

Objectives: The aim of this research was to observe the effect of Javanese turmeric ethanol extract (JTEE) on the eradication of Candida albicans in various phases of biofilm development.

Methods: C. albicans biofilms were exposed to JTEE at a concentration 1-45\% for $1 \mathrm{~h}$. Cell viability was tested by 3-(4,5-dimethylthiazol-2-yl)-2,5diphenyltetrazolium bromide assay, and the wavelength was read at $570 \mathrm{~nm}$.

Results: The results showed that the $50 \%$ minimal biofilm eradication concentration was $30 \%$ in the early phase, $20 \%$ in the intermediate phase, and $25 \%$ in the maturation phase of the biofilm. The eradication percentage increased along with increasing JTEE concentration, but decreased with the age of the biofilm.

Conclusion: We concluded that JTEE has the potential to eradicate $C$. albicans biofilms in various phases of development.

Keywords: Biofilm, Candida albicans, Javanese turmeric ethanol extract.

(C) 2019 The Authors. Published by Innovare Academic Sciences Pvt Ltd. This is an open access article under the CC BY license (http://creativecommons. org/licenses/by/4. 0/) DOI: http://dx.doi.org/10.22159/ijap.2019.v11s1.148

\section{INTRODUCTION}

Candida albicans is a commensal fungus in the oral cavity and is present as about $50 \%$ of the oral microflora [1]. However, in certain circumstances, such as during disturbances in the balance of oral microflora or decreased immune defenses, $C$. albicans may turn into an opportunistic pathogen [1]. The oral mucosa provides a good habitat for microorganisms including Candida to inhabit because of the availability of favorable environmental conditions for the colonization process [2]. Candida infections of the oral mucosa lead to the formation of white plaque lesions commonly known as candidal leukoplakia, but can also form reddish areas, such as in stomatitis, associated with the use of dentures [1].

Oral candidiasis is the most prevalent opportunistic infection of the oral mucosa, and C. albicans possesses various virulence factors that contribute to its ability to infect oral tissues [2]. These factors include phenotypic switching, adhesion, morphological dimorphism, and hydrolytic enzyme secretion $[2,3]$.

Biofilms are microbial communities embedded in a polymer matrix that develop after attachment to a surface [4]. They protect microorganisms from host immune cells and antimicrobial agents [5]. C. albicans biofilms inhibit the penetration of antibiotics and prevent them from reaching their target cells [5]. The C. albicans biofilm formation occurs in several developmental stages: early $(0-11 \mathrm{~h})$, intermediate $(12-30 \mathrm{~h})$, and maturation (38-72 h) phases [6]. Biofilm extracellular matrix increases overtime to become multilayer consists of yeast cells, pseudohyphae, and hyphae. The hyphal cells play an important role because they can produce hydrolytic enzymes, such as secreted aspartyl proteinase and phospholipases that contribute to host-cell damage. It is also known that antifungal resistance increases with biofilm development, and this is associated with increasing metabolic activity during biofilm development, as revealed by a study using $C$. albicans biofilms with a high resistance to antifungal agents, such as fluconazole and nystatin [6].
Oral candidiasis can be treated locally, for example, using topical antibiotics to remove the white plaques or using nystatin or amphotericin lozenges to manipulate the oral microflora and return the balance [1]. Nystatin is the drug used as the gold standard for oral candidiasis, and fluconazole is an alternative option.

Javanese turmeric (Curcuma xanthorrhiza Roxb.) is one of Indonesia's leading medicinal plants and is currently being tested by the Food and Drug Supervisory Agency [7]. One of its active agents is xanthorrhizol [8]. A previous study showed that xanthorrhizol has many medical properties, including being an antimicrobial, anti-inflammatory, antioxidant, antihyperglycemic, antihypertensive, and anticoagulant [9]. Another study also showed that xanthorrhizol isolated from C. zanthorrhiza Roxb. has an antifungal effect with minimum inhibitory concentration (MIC) of 1-15 mg/l and minimum fungicidal concentration (MFC) of $200 \mathrm{mg} / \mathrm{ml}$ toward C. albicans [10].

Research on the medical effects of Javanese turmeric extract as a potential agent against $C$. albicans was initiated several years ago at the Faculty of Dentistry, University of Indonesia. In a research conducted by Pramudita, Javanese turmeric ethanol extract (JTEE) was shown to inhibit the activity of phospholipase enzymes produced by $C$. albicans at a concentration of $2.5 \mathrm{mg} / \mathrm{l}$ using shake handling [11]. Lewiyonah and Herdiantoputri reported the MIC and MFC of JTEE toward planktonic C. albicans and showed that, at a concentration of 35\%, JTEE reduced the ability of $C$. albicans to enter the adhesion, proliferation, filamentation, and maturation phases within $24 \mathrm{~h}[12,13]$. This study aimed to observe the effect of JTEE on the eradication of $C$. albicans in the early, intermediate, and maturation phases of biofilm development.

\section{METHODS}

C. albicans (ATCC 10231) was obtained from the Oral Biology Laboratory of the Faculty of Dentistry, University of Indonesia, and was grown in Petri dishes on Sabouraud dextrose agar (SDA) for $48 \mathrm{~h}$ at $37^{\circ} \mathrm{C}$. Dishes 
were stored at $4^{\circ} \mathrm{C}$ until use. C. albicans suspensions were prepared from stock dishes by inoculating $1 \mathrm{ml}$ of Sabouraud dextrose broth (SDB) with three loops of an inoculation needle and homogenization by vortexing for $20 \mathrm{~s}$.

JTEE (Balittro, Indonesia) was processed by centrifugation at $1300 \mathrm{rpm}$ for $20 \mathrm{~min}$ at $4^{\circ} \mathrm{C}$ to form three layers. The upper layer, which contains the highest xanthorrhizol concentration, was used and diluted to $1 \%$, $5 \%, 10 \%, 15 \%, 20 \%, 25 \%, 30 \%, 35 \%, 40 \%$, and $45 \%$.(v/v) in SDB. After vortexing for $20 \mathrm{~s}$, the JTEE samples were stored at $4^{\circ} \mathrm{C}$ until further use.

For biofilm preparation, three well plates were prepared, one for each biofilm phase. Each well was seeded with $100 \mu \mathrm{l}$ of $10^{4}$ cells. The plates were then incubated at $37^{\circ} \mathrm{C}$ for $6 \mathrm{~h}$ to produce the initial phase, $24 \mathrm{~h}$ for the intermediate phase, or $48 \mathrm{~h}$ for the maturation phase. Once biofilms were established, the medium was aspirated to remove planktonic C. albicans, and the plates were rinsed once with $100 \mu \mathrm{l}$ of phosphatebuffered saline (PBS).

Various JTEE dilutions $(100 \mu \mathrm{l})$ were added to the biofilms in the wells, and $100 \mu \mathrm{l}$ of nystatin (10000 units in SDB) was used as a positive control. SDB was used as the negative control. The plates were then incubated for $1 \mathrm{~h}$ at $37^{\circ} \mathrm{C}$ and then rinsed once with $100 \mu \mathrm{l}$ of PBS.

Following this, $10 \mu \mathrm{l}$ of $5 \mathrm{mg} / \mathrm{ml} \mathrm{3-(4,5-dimethylthiazol-2-yl)-2,5-}$ diphenyltetrazolium bromide was added to each well, and the plates were incubated at $37^{\circ} \mathrm{C}$ for $2 \mathrm{~h}$. Following incubation, $100 \mu \mathrm{l}$ acidified isopropanol was added, and the plates were shaken on an orbital shaker at $80 \mathrm{rpm}$ for $1 \mathrm{~h}$. Optical absorbance was determined using a microplate reader a $570 \mathrm{~nm}$, and the biofilm eradication was expressed as a percentage of the control using the formula:

$$
\left(1-\left[\frac{\text { ODsample-ODblanksample }}{\text { ODcontrol-ODblankcontrol }}\right]\right) \times 100 \%
$$

Minimal biofilm eradication concentration (MBEC) was determined as the concentration that produced eradication values of $50 \%\left(\mathrm{MBEC}_{50}\right)$ or $90 \%\left(\mathrm{MBEC}_{90}\right)$.

ANOVA with a post hoc test was used to analyze the data obtained. Data analysis was performed using SPSS Software to compare the difference between eradication percentage of biofilm treated with JTEE and the positive control (nystatin). A correlation test was used to determine whether there was a correlation between increasing JTEE concentration and biofilm eradication percentage.

\section{RESULTS}

Before JTEE was tested on C. albicans biofilms, the MIC and MFC toward planktonic $C$. albicans were determined by measuring optical densities using a microplate reader to determine the percentage inhibition at each JTEE concentration. MIC is the smallest concentration that can inhibit the growth of C. albicans by $90 \%$ or more, and this was found to be $20 \%$ JTEE (Table 1 ).

After determining MIC, $10 \mu \mathrm{l}$ C. albicans that had been exposed to JTEE was inoculated into SDB agar medium and grown, and the number of colonies was counted to determine MFC, which was also found to be $20 \%$ (Table 2).

JTEE was able to eradicate more than $50 \%$ C. albicans in biofilms at all three stages of biofilm development at all concentrations, except at $20 \%$ on the 6-h biofilms. However, statistical analysis showed that not all of the concentrations were significantly different from the positive control. The results of ANOVA statistical analysis showed that there was no significant difference in the eradication percentage in the 6-h biofilms between the positive control and the 30\% and 35\% JTEE concentrations ( $p>0.05$ ). The 24-h biofilms exposed to JTEE at 20\%, $25 \%, 35 \%, 40 \%$, and $45 \%$ gave similar results to 48 -h biofilms exposed
Table 1: Inhibition percentage of planktonic Candida albicans growth by Javanese turmeric ethanol extract at various concentrations

\begin{tabular}{lllll}
\hline \multirow{2}{*}{ Number } & JTEE concentration (\%) & \multicolumn{3}{l}{ Inhibition (\%) } \\
\cline { 3 - 5 } & & $\mathbf{I}$ & $\mathbf{I I}$ & $\mathbf{X}$ \\
\hline 1 & 1 & 18.68 & 16.99 & 17.835 \\
2 & 5 & 3.86 & 4 & 3.93 \\
3 & 10 & 15.22 & 13.52 & 14.37 \\
4 & 15 & 80.88 & 73.3 & 77.09 \\
5 & $20^{*}$ & 95.51 & 98.91 & 97.21 \\
6 & 25 & 31.85 & 30.89 & 31.37 \\
7 & 30 & 98.61 & 84.08 & 91.345 \\
8 & 35 & 90 & 90.81 & 90.405 \\
9 & 40 & 95.62 & 92.63 & 94.125 \\
10 & 45 & 98.61 & 88.36 & 93.485 \\
11 & Positive control & 97.44 & 97.01 & 97.225 \\
12 & Negative control & 0 & 0 & 0 \\
\hline *JTEE: Javanese turmeric ethanol extract & & &
\end{tabular}

Table 2: Minimum fungicidal concentration of Javanese turmeric ethanol extract toward planktonic Candida albicans

\begin{tabular}{lllll}
\hline \multirow{2}{*}{ Number } & JTEE concentration (\%) & \multicolumn{3}{l}{ Colonies (n) } \\
\cline { 3 - 5 } & & I & II & X \\
\hline 1 & 20 & 0 & 0 & 0 \\
2 & 25 & 4 & 61 & 32.5 \\
3 & 30 & 0 & 0 & 0 \\
4 & 35 & 0 & 0 & 0 \\
5 & 40 & 0 & 0 & 0 \\
6 & 45 & 0 & 0 & 0 \\
7 & Positive control & 0 & 0 & 0 \\
8 & Negative control & $\infty$ & $\infty$ & $\infty$ \\
\hline JTEE: Javanese turmeric ethanol extract & & &
\end{tabular}

to JTTE at $25 \%, 35 \%$, and $40 \%$ concentrations. Therefore, the $\mathrm{MBEC}_{50}$ of JTTE was 30\%, 20\%, and 25\% against the 6-h, 24-h, and 48-h C. albicans biofilms, respectively. The $\mathrm{MBEC}_{90}$ could not be determined because it was considered biased.

Linear regression fitting of the 6 -h biofilm produced a correlation coefficient of $r=0.703$, indicating a strong relationship between concentration and eradication values. Correlation coefficients were smaller for the 24-h and 48-h biofilms with values of 0.296 and 0.524 , respectively. The correlations were all positive although the increases in concentrations were not always followed by ideal eradicating values.

\section{DISCUSSION}

The high polarity of ethanol as well as its hydrophobic ethyl group makes it ideal for extracting the active substances of Javanese turmeric rhizomes, including polar, nonpolar, and phenolic components. The method used in manufacturing the ethanol extract was the stirringmaceration technique, which can speed up extraction times by 6-24 h and thus reduce decomposition due to temperature effects [14].

Although the ethanol extract used in this study was obtained from the same place and produced by the same method and with the same solvent, there were physical differences between it and that used in a previous study in $2015[12,13]$. In this previous study, JTEE was a homogenous, yellowish-brown liquid with a unique smell $[12,13]$. In contrast, JTEE in this study had two different appearances mixed into one. In one container, the ethanol extract obtained had clay consistency and yellowish-brown color. In the previous study, the ethanol extract was centrifuged at $3000 \mathrm{rpm}$ for $20 \mathrm{~min}$ and yielded four layers with xanthorrhizol concentration of $41.8 \%$, whereas, in this study, the extract was centrifuged at $3000 \mathrm{rpm}$ but did not yield similar layers. Thus, the centrifugation of the ethanol extract was modified to $1300 \mathrm{rpm}$ for 
20 min, which yielded three layers with a xanthorrhizol concentration of $9.38 \%$.

This difference of the Xanthorrhizol content in the Javanese turmeric extract used in the two studies was likely due to a difference in the amount of Javanese turmeric in kilograms demanded during extract preparation. It has been reported that the active substances in every Javanese turmeric extract differ because of differences in the fertilizer type used in cultivation, which can affect the content of essential oils, curcumin, and xanthorrhizol [15]. The higher the essential oil content of the simplicial, the better is its quality because all medicinally active substances are contained in the essential oils. In addition, the quality and active ingredients of Javanese turmeric plants are also influenced by other factors such as the growing environment, superior properties of the plants, availability of nutrients, protection provided against pest organisms, and postharvesting treatment [16].

To produce various concentrations of JTEE used in this study, SDB was used as a solvent, unlike a previous study by Lewiyonah that used dimethyl sulfoxide (DMSO) [13]. Even though 10\% DMSO is known to be nontoxic, the extract could not be dissolved well in DMSO in this study and precipitated rapidly. The test was conducted on three phases of biofilm formation, i.e., the initial ( $6 \mathrm{~h})$, medium $(24 \mathrm{~h})$, and maturation $(24 \mathrm{~h})$ phases, and the biofilms were exposed to JTEE for $1 \mathrm{~h}$. SDA and SDB media were used because they are standard media for growing $C$. albicans because of the presence of glucose and acidic $\mathrm{pH}$ [17]. C. albicans were grown at $37^{\circ} \mathrm{C}$ for $48 \mathrm{~h}$ as this temperature reflected the temperature of the oral cavity and was able to stimulate hyphae formation [18].

The MIC and MFC of JTEE toward planktonic $C$. albicans in this study were at $20 \%$. This differed from Lewiyonah, who reported an MIC and MFC of $10 \%$ and $25 \%$, respectively [13]. These differences may have been due to the differences in the concentrations of the ethanol extracts and their xanthorrhizol contents.

The microtiter broth dilution method was chosen to determine the MIC and MFC of JTEE toward planktonic C. albicans. To obtain inhibition percentage values, proliferation of $C$. albicans starting with $10^{4}$ cells was monitored by measuring optical density at $450 \mathrm{~nm}$. This method was chosen because it is convenient and accurate when compared to the agar dilution method, which produces inconsistent results.

The concentrations of JTEE used in this study were 1-45\%. Although the values for MIC and MFC determined in this study differed to those reported by Lewiyonah [13], similar trends in inhibition with increasing JTEE concentration were observed.

However, due to inconsistencies of eradication effect of the extract against $C$. albicans biofilm at some concentration, it is not possible to conclude that the inhibition effect of the extract was dose dependent. In a previous work, JTEE was produced from $6 \mathrm{~kg}$ of Javanese turmeric rhizomes that were dissolved in pure ethanol, whereas this study only used $3 \mathrm{~kg}$ of rhizome dissolved in $90 \%$ ethanol. The ethanol extract used by Lewiyonah in the previous study had a xanthorrhizol concentration of $41.8 \%$. In contrast, in this study, the ethanol extract concentration was $9.38 \%$. This may have occurred because, eventhough the Javanese turmeric extract used were processed at the same laboratory, different shapes and properties accepted due to the different amount of demanded rhizomes in kilograms, thereby affecting the final outcome of the study. The quality and active ingredients of Javanese turmeric plants are also influenced by other factors described above [16].

Xanthorrhizol is known to inhibit the growth of microorganisms. Hwang (2006) showed that xanthorrhizol isolated from Javanese turmeric is antifungal against planktonic Streptococcus mutans. The results of this study showed that the JTEE containing only $9.38 \%$ xanthorrhizol could still inhibit growth of $C$. albicans biofilm. The hydroxyl groups $(-\mathrm{OH})$ found in nystatin are known to induce damage to the plasma membrane of $C$. albicans cells by binding to ergosterol and oxidizing the membrane lipids, leading to permeabilization, cell leakage, potassium ion release, and eventual cell death [19]. The same mechanism may be responsible for xanthorrhizol's antifungal activity.

In this study, JTEE eradicated $C$. albicans cells in all three phases of biofilm formation when compared to the controls. The MBEC values of JTEE on 6-h, 24-h, and 48-h biofilms were 30\%, 20\%, and $25 \%$, respectively. These results were assumed to occur via similar mechanisms to those that affected planktonic $C$. albicans. Thus, JTEE efficacy was high in the initial phase, decreased in the intermediate phase, and increased again in maturation phase. In contrast, previous studies have linked increased antifungal resistance with stages of biofilm development, suggesting that resistance progression develops over time along with biofilm maturation.

It is known that more mature biofilms produce more complex extracellular matrices, which allows them to become more resistant to antifungal agents. This was assumed to occur because, in the early phase of biofilm formation, $C$. albicans cells have a higher metabolic activity as they are actively growing; therefore, it took a higher concentration of JTEE to suppress the growth. This then decreased in the intermediate phase and increased again in the maturation phase. This may occur because, as reported by Henriques et al., cell activity of a biofilm is not dependent on the number of cells present [20]. In a biofilm, the cells are surrounded by an extracellular matrix that limits the access of nutrients and oxygen, resulting in alterations to cellular metabolic activity. As biofilm mass increases over time while activity decreases, biofilms in the maturation phase may contain large numbers of cells, but these cells have low metabolic activity.

The eradication percentage of $C$. albicans biofilms by JTEE at 6-h, 24-h, and 48-h was lower than the positive control, but these differences were not statistically significant. Thus, JTEE has the potential to eradicating biofilms but not as well as nystatin. Previous study showed that the exposure of $S$. mutans biofilms to xanthorrhizol for $1 \mathrm{~h}$ was sufficient to eradicate as much as $76 \%$ of the biofilms [21].

Although not completely eliminated, bacteria were removed in the adhesion phase and early accumulation of biofilm development [21]. Killed cells will degrade and detach from the biofilm, resulting in a decrease in its cell content [21]. Henriques et al. suggested that C. albicans biofilm organization generally resembles the biofilm structures of oral bacterial species; therefore, a similar mechanism may occur in xanthorrhizol-mediated eradication of C. albicans biofilms [20].

\section{CONCLUSION}

The results of this study indicate that the MIC and MFC of JTEE toward planktonic $C$. albicans after 1 h exposure are 20\%. JTEE had the potential to eradicate $C$. albicans biofilms at any of the three phases of biofilm formation after $1 \mathrm{~h}$ of exposure.

\section{CONFLICT OF INTEREST}

The authors report no conflict of interest.

\section{REFERENCES}

1. Cawson R, Odell EW. Cawson's Essentials of Oral Pathology and Oral Medicine. $7^{\text {th }}$ ed. London: Elsevier Science Limited; 2002

2. Tyasrini E, Winata T, Susantina D. Relationship between properties and metabolite of Candida Spp. J Knowl Manag 2006;6:52-67.

3. Nett J, Lincoln L, Marchillo K, Massey R, Holoyda K, Hoff B, et al. Putative role of beta-1,3 glucans in Candida albicans biofilm resistance. Antimicrob Agents Chemother 2007;51:510-20.

4. Hetrick EM, Shin JH, Paul HS, Schoenfisch MH. Anti-biofilm efficacy of nitric oxide-releasing silica nanoparticles. Biomaterials 2009;30:2782-9.

5. Chandra J, Kuhn DM, Mukherjee PK, Hoyer LL, McCormick T, Ghannoum MA, et al. Biofilm formation by the fungal pathogen Candida albicans: Development, architecture, and drug resistance. 
J Bacteriol 2001;183:5385-94

6. Falah-Tafti A, Jafari AA, Lotfi-Kamran MH, Fallahzadeh H, Hayan RS. A comparison of the eFficacy of nystatin and fluconazole incorporated into tissue conditioner on the in vitro attachment and colonization of Candida albicans. Dent Res J (Isfahan) 2010;7:18-22.

7. BPOM. National movement of drinking Curcuma zanthorrhiza. Info POM 2005;6:1-12.

8. Rohaimi M, Halim AB, Muhammad S, Tan Z, Ismail S, Mahmud R. Standardization and phytochemical studies of Curcuma xanthorrhiza Roxb. Int J Pharm Pharm Sci 2012;4:606-10.

9. Oon SF, Nallappan M, Tee TT, Shohaimi S, Kassim NK, Sa'ariwijaya MS, et al. Xanthorrhizol: A review of its pharmacological activities and anticancer properties. Cancer Cell Int 2015;15:100.

10. Rukayadi Y, Yong D, Hwang J. In vitro anticandidal activity of xanthorrhizol isolated from Curcuma xanthorrhiza Roxb. J Antimicrob Chemother 2006;57:1231-4.

11. Pramudita S. Effect of Curcuma xanthorrhiza Roxb. Ethanol Extract on Phospholipase Enzym Activity and Candida albicans Biofilm Development. Undergraduate Thesis. Jakarta: Universitas Indonesia; 2009

12. Herdiantoputri RR. Antifungal Effect of Curcuma xanthorrhiza Roxb. Ethanol Extract on Candida albicans during Filamentation and Maturation Phases Undergraduate Thesis. Jakarta: Univeristas Indonesia; 2015.

13. Lewiyonah R. Antifungal Effect of Curcuma xanthorrhiza Roxb. Ethanol Extract on Candida albicans during Adhesion dan Proliferation
Phases Undergraduate Thesis. Jakarta: Universitas Indonesia; 2015.

14. Anggakusuma Y, Lee M, Hwang JK. Estrogenic activity of xanthorrhizol isolated from Curcuma xanthorrhiza ROXB. Biol Pharm Bull 2009;32:1892-7.

15. Fibrianty, Hatmi RU. Effect of fertilization on the quality of Curcuma xanthorrhiza Simplicia in Kulon Progo, Yogyakarta. Balai Pengkaj Teknol Pertani Yogyakarta 2011;22:137-41.

16. Rahardjo M. Application of standard operational procedure in Curcuma xanthorrhiza cultivation to support it as raw materials for potential drugs. Bull Res Herbs Med Plants 2010;9:78-93.

17. Karkowska-Kuleta J, Rapala-Kozik M, Kozik A. Fungi pathogenic to humans: Molecular bases of virulence of Candida albicans, Cryptococcus neoformans and Aspergillus fumigatus. Acta Biochim Pol 2009;56:211-24.

18. Tsang PW, Bandara HM, Fong WP. Purpurin suppresses Candida albicans biofilm formation and hyphal development. PLoS One 2012;7:e50866.

19. Brautaset T, Sletta H, Degnes KF, Sekurova ON, Bakke I, Volokhan O, et al. New nystatin-related antifungal polyene macrolides with altered polyol region generated via biosynthetic engineering of Streptomyces noursei. Appl Environ Microbiol 2011;77:6636-43.

20. Henriques M, Azeredo J, Oliveira R. Candida albicans and Candida dubliniensis: Comparison of biofilm formation in terms of biomass and activity. Br J Biomed Sci 2006;63:5-11.

21. Rukayadi Y, Hwang JK. In vitro activity of xanthorrhizol against Streptococcus mutans biofilms. Lett Appl Microbiol 2006;42:400-4. 